\title{
Aspirin and stroke prevention: How much?
}

\author{
GILBERT J. TOFFOL, DO
}

Media attention concerning aspirin and the prevention of heart attack has been great, but there has been no similar attention to the subject of aspirin and stroke prevention. Clinical information is available in the literature concerning aspirin dosage and stroke prevention following transient ischemic attack (TIA). However, confusion still exists regarding appropriate dosing as well as the effectiveness of other antiplatelet agents. This review focuses on the mechanism of action of aspirin and cites the rationale provided by clinical trials for a recommendation of $1300 \mathrm{mg}$ of aspirin per day as the sole orally administered antiplatelet agent.

The correct dosage of aspirin to be used in the treatment of cerebrovascular and cardiovascular disease is a subject of controversy. The media blitz concerning aspirin has nearly run its course, but public awareness of the issue has been heightened. Clinicians are still waiting for specific dosage recommendations because pharmaceutical advertising does not provide such guidelines. Media attention was given to two studies of aspirin in the prevention of heart attack, ${ }^{1,2}$ while the media ignored previous studies regarding aspirin and stroke prevention. ${ }^{3,4}$

As of this writing, there are two large, mul-

Dr Toffol is a clinical assistant professor at the College of Osteopathic Medicine of the Pacific, Pomona, Calif, and a fellow of the American heart Association Stroke Council.

Reprint requests to Gilbert J. Toffol, DO, Valley Neurology Associates, 4244 N 19th Ave, Phoenix, AZ 85015 ticenter clinical studies comparing aspirin and carotid endarterectomy for efficacy in stroke prevention. Also, the results of a study comparing ticlopidine hydrochloride versus aspirin in stroke prevention have recently been published, ${ }^{5}$ again focusing medical and public attention on antiplatelet therapy.

Aspirin therapy is the preferred form of medical treatment for most patients with transient ischemic attack (TIA). Aspirin inhibits platelet aggregation by nonselectively blocking the enzyme cyclooxygenase, which is an important rate-limiting enzyme in the arachidonic acid cascade. ${ }^{6,7}$ Cyclooxygenase converts arachidonic acid to prostaglandin endoperoxides and, eventually, to thromboxane A2, which activates platelet aggregation. Aspirin also influences the course of arteriosclerosis by inhibiting the release of platelet-derived growth factor.

The optimal conventional aspirin dose for stroke prevention is $1300 \mathrm{mg} /$ day, but a lower dose may be better on theoretical grounds. ${ }^{8}$ Despite well-established reports, ${ }^{3,4,9}$ controversy exists as to the amount of aspirin that should be prescribed. This might be attributed to the fact that the lower dosage of aspirin prescribed for heart attack prevention is inadvertently being applied to patients with TIA and stroke. Thus, the cerebrovascular literature has been relatively ignored. This article will explore the recommended dosage by reviewing past reports and recent trials aimed at averting strokes.

\section{Discussion}

In 1977 and 1978, American and Canadian studies showed a statistically significant benefit 
of using aspirin in stroke prevention after transient ischemia attack. ${ }^{3,4}$ Each of these studies used $1300 \mathrm{mg}$ of aspirin daily and demonstrated a $25 \%$ to $48 \%$ reduction in stroke after TIA. The beneficial effect was highest in men, but other studies have demonstrated a benefit for women. ${ }^{10,11}$ Apparently, regardless of treatment, the incidence of cerebrovascular disease is lower in women than in men. The American study also showed that a subpopulation of patients with carotid ulcerative plaque received strong benefits from aspirin. ${ }^{3}$

Many physicians and surgeons were taken aback by the definitive results of an international landmark clinical trial showing no beneficial effect from surgery compared with aspirin in symptomatic patients with carotid occlusion or middle cerebral artery stenosis. The aspirin therapy consisted of $325 \mathrm{mg}$ taken four times daily. ${ }^{9}$

In 1988, an aspirin trial by the United Kingdom-TIA study group showed no difference between a $300-\mathrm{mg}$ and a $1200-\mathrm{mg}$ daily dose of aspirin with respect to events. ${ }^{12}$ However, the fundamental analysis of the study was changed twice regarding patients and methods. ${ }^{12}$ The data chosen were difficult to interpret as presented in the report. Nonfatal myocardial infarctions, nonfatal major strokes, vascular deaths and nonvascular deaths were grouped together and both the $300-\mathrm{mg}$ and the 1200 -mg daily doses were considered together in the analysis. The responses to $300 \mathrm{mg}$ and $1200 \mathrm{mg}$ of aspirin daily were similar, except that the lower dose was significantly less gastrotoxic.

There might have been some bias toward the $300-\mathrm{mg}$ dose because another report showed this dosage to be beneficial in British male physicians. ${ }^{2}$ In addition, Peto, the coprincipal investigator of the United KingdomTIA study, ${ }^{12}$ assumed no systemic differences, weighted all vascular events equally, and concluded that antiplatelet therapy reduces the risk of nonfatal vascular events and, to a lesser extent, vascular death. Cerebrovascular disease should be viewed independently because it is the third largest cause of death in much of the industrial world. A benefit to one type of vascular event does not necessarily mean a benefit to all. Accepting the conclusions of this study's complex analysis is difficult. The final opinion would have been reasonable if the authors had considered one major event, such as stroke.

Other platelet antiaggregants have shown no additional benefit when added to aspirin therapy. In the Canadian study, sulfinpyrazone was found to be no more effective than placebo. ${ }^{4}$ Results at fifteen centers throughout the United States and Canada showed that the addition of dipyridamole contributes no additional benefit for TIA patients taking aspirin. ${ }^{11}$ In addition, dipyridamole is unlikely to contribute to the prevention of acute myocardial infarction or to maintaining the patency of saphenous vein aortocoronary-bypass grafts. ${ }^{13}$

Nevertheless, a European Stroke Prevention Study showed a $33 \%$ benefit in favor of combining aspirin at $975 \mathrm{mg} /$ day with dipyridamole at $225 \mathrm{mg} /$ day. ${ }^{14}$ Because of methodologic uncertainties, this study is open to criticism. The population baselines studied were not subcategorized prior to treatment. Some 639 randomized patients $(26 \%)$ were declared ineligible halfway through the study. Also, 800 patients dropped out within 24 months. Apparently, for reasons not stated, these patients were nevertheless included in the final analysis, but one cannot be certain of this from a reading of the paper.

In persons older than 40 , or even 50 years, who do not have symptoms of heart disease or cerebrovascular disease, it is not advisable to recommend aspirin. Only after a thorough history and both physical and paraclinical examinations documenting atherosclerosis, should aspirin be prescribed. In the two physician aspirin studies mentioned at the beginning of this report, ${ }^{1,2}$ intraparenchymal hemorrhage was noted as a complication, but the numbers of patients affected were small and not significant.

This finding has not been reported in previous aspirin or antiplatelet trial studies. Even though the aspirin-associated cerebral hemorrhages reported are tentative, aspirin should not be recommended empirically unless cardiac or carotid atherosclerosis is found on physi- 
cal examination, noninvasive studies, or contrast angiography. If used, aspirin should be considered a possible adjunct, but not an alternative, to risk factor modification, which includes smoking cessation, lowering cholesterol levels, and reducing blood pressure. ${ }^{15}$

\section{Conclusion}

The current recommended daily dosage of aspirin for stroke prevention is still $325 \mathrm{mg}$ four times daily or $650 \mathrm{mg}$ twice daily. One 325 $\mathrm{mg}$ aspirin tablet daily is a reasonable compromise for those patients with aspirin-induced gastric intolerance. Coated aspirin or aspirin combined with antacid can also be considered. There is no benefit to adding sulfinpyrazone or dipyridamole to aspirin for stroke and heart attack prevention.

Blanket statements that aspirin should be given automatically to patients who have reached age 40 or 50 have no sound basis and might be potentially fatal. On the other hand, when a patient history and findings of physical examination, as well as the results of other investigative tests, document cerebrovascular or cardiovascular disease, aspirin therapy would be appropriate.

\footnotetext{
1. Steering Committee of the Physicians' Health Study Research Group: Final report: Findings from the aspirin component of the ongoing Physicians' Health Study. N Engl J Med 1989;321:129-135.

2. Peto R, Gray R, Collins R, et al: Randomized trial of prophy-
}

lactic aspirin in British male doctors. $B r$ Med $J$ 1988;296:313 316.

3. Fields WS, Lemak NA, Frankowski RF, et al: Controlled trial of aspirin in cerebral ischemia. Stroke 1977;8(3):301-314.

4. Canadian Cooperative Study Group: A randomized trial of aspirin and sulfinpyrazone in threatened stroke. $N$ Engl J Med 1978;299:53-59.

5. Hass WK, Easton JD, Adams HP, et al: A randomized trial comparing ticlopidine hydrochloride with aspirin for the prevention of stroke in high risk patients. $N \mathrm{Engl} J \mathrm{Med}$ 1989;321:501-507.

6. Roth GJ, Maferus PW: The mechanism of the effect of aspirin on human platelet: I. Acetylation of a particulate fraction protein. J Clin Invest 1975;56:624-632.

7. Roth GJ, Stanford N, Majerus PW: Acetylation of prostaglandin synthetase by aspirin. Proc Natl Acad Sci USA 1975;72:30373076 .

8. Hirsh J: Progress review: The relationship between dose of aspirin, side effects and antithrombotic effectiveness. Stroke $1985 ; 16: 1-4$.

9. EC/IC Bypass Study Group: Failure of extracranial-intracranial arterial bypass to reduce the risk of ischemic stroke: Results of an international randomized trial. $N$ Engl J Med 1985;313:1191-1200.

10. Bousser MG, Eschwege E, Haguenau M, et al: "AICLA" controlled trial of aspirin and dipyridamole in the secondary prevention of athero-thrombotic cerebral ischemia. Stroke 1983;14:514.

11. American-Canadian Co-Operative Study Group: Persantine aspirin trial in cerebral ischemia: Part II. Endpoint results. Stroke 1985;16:406-415.

12. UK-TIA Study Group: United Kingdom Transient Ischaemic Attack (UK-TIA) aspirin trial: Interim results. $\mathrm{Br} \mathrm{Med} J$ 1988;296:316-320.

13. Fitzgerald GA: Dipyridamole. NEngl J Med 1987;316:12471256.

14. European Stroke Prevention Study: Principal end-points. Lancet 1987;2:1351-1354.

15. Young FE, Nightingale SL, Temple RA: The preliminary report of the findings of the Aspirin Component of the Ongoing Physicians' Health Study: The FDA perspective on aspirin for the primary prevention of myocardial infarction. JAMA 1988;259:3158-3160. 


\section{FROM THE WORK OF A FEW FOR THE BENEFIT OF MANY}

"... The whole of my remaining realizable estate shall be dealt with in the following way: the capital, invested in safe secu- Nom: rities by my executors, shalf constitute a fund, the interest on which shall be annually distributed in the form of prizes to those who, during the preceding year, shall have conferred the greatest benefit on mankind..."
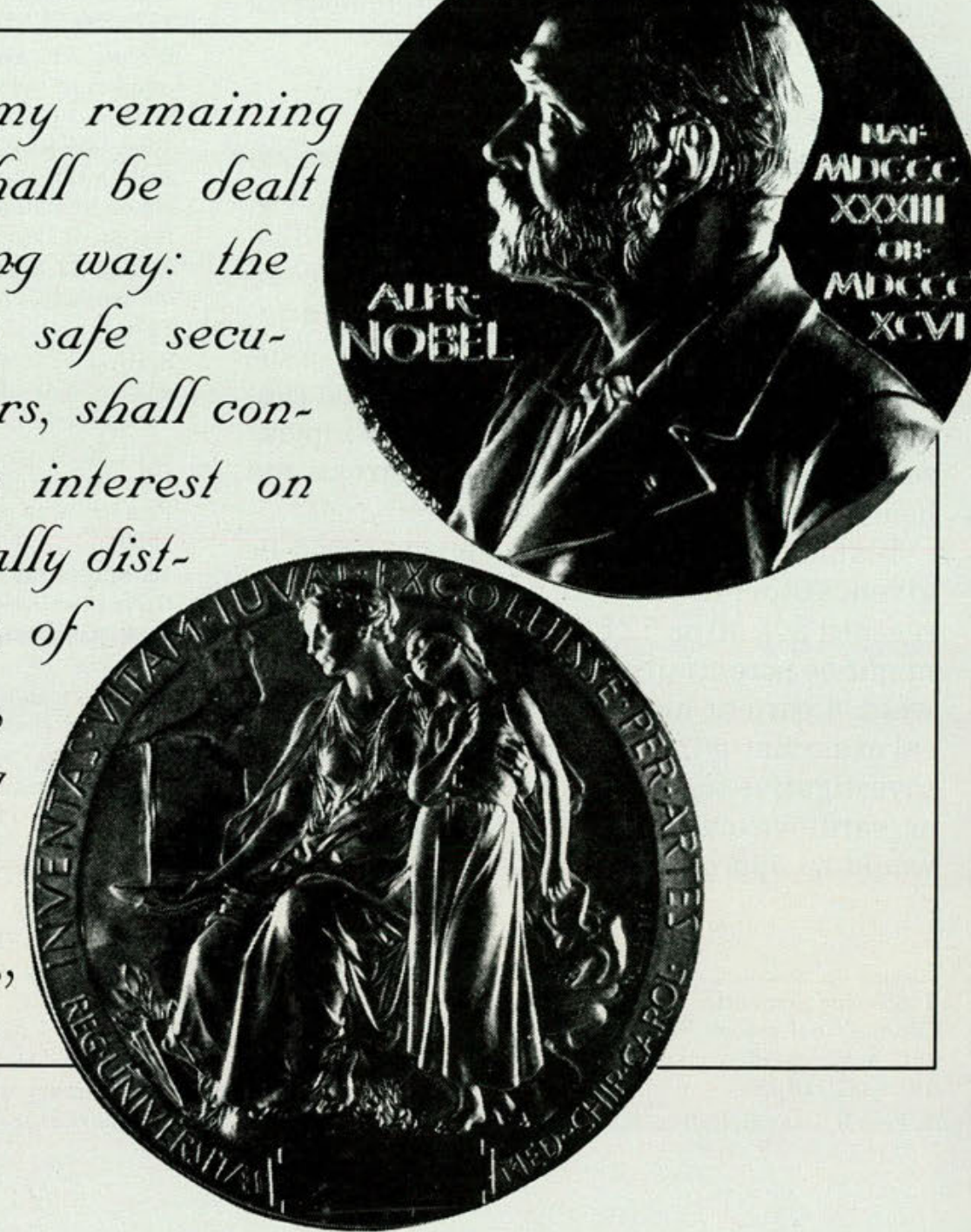

With these words from his Last Will and Testament in 1895, Alfred Nobel linked the two vital elements in the formula for excellence: minds driven to discovery and capital to fund the quest.

At research-based pharmaceutical companies, Nobel laureates of yesterday, today and tomorrow work in an environment that nurtures innovation and faithfully follows Nobel's winning formula: creative minds supported by over $\$ 7$ billion research dollars. The result benefits us all and enhances the quality of our lives, through major medical breakthroughs and the development of new and better drugs. 